\title{
JURISPRUDENCIA AMBIENTAL EN EXTREMADURA (SEGUNDO SEMESTRE 2016)
}

\author{
Pedro BRUfao CURIEL \\ Profesor Contratado Doctor de Derecho Administrativo \\ Universidad de Extremadura
}

Desde abril de 2016 se han publicado algunas interesantes sentencias penales sobre cuestiones ambientales que pasamos a describir a continuación.

En primer lugar, el medio ambiente urbano encuentra cada vez más acogida en nuestros tribunales. Una muestra de ello es la SAP de Cáceres, Sección 2a n $^{\circ}$ 156/2016, de 19 de mayo de 2016, que estima parcialmente el recurso contra una sentencia del Juzgado de Plasencia recaída sobre la ampliación de un edificio en una parcela declarada como "suelo urbano no consolidado" en un municipio de La Vera. Esta sentencia cuenta con cierta particularidad respecto del empleo que se da en la jurisdicción penal de conceptos eminentemente administrativos, como los relativos al Derecho urbanístico, la clave en este asunto.

En efecto, se trataba de enjuiciar la licitud penal de un particular que amplió su vivienda y de un edil que autorizó contra legem dichas obras, consistentes en "la ampliación de una terraza, tabiquería, cerramientos, solados, revestimientos y carpintería interior y exterior para salón, dormitorio y ampliación de aseo para la instalación de plato de ducha [...] sin contar con el preceptivo informe por parte de los Servicios Técnicos Municipales en materia urbanística y a pesar de obrar expresa advertencia respecto a la improcedencia de su otorgamiento, precisamente por esa la falta de dictamen técnico antecedente, por parte del Secretario del Ayuntamiento, y constándole expresamente al acusado que la autorización de dicho permiso de obra sería contraria a Derecho, al haber sido advertido de ello en diversas reuniones mantenidas, desde al año 2001, con los responsables de la Oficina de Gestión Urbanística de la mancomunidad intermunicipal de La Vera”.

La Audiencia Provincial tiene en cuenta de que se trata de una obra menor y de que el Juzgado de lo Penal $\mathrm{n}^{\circ} 1$ de Plasencia confundió la clase del suelo (equivocadamente 
suelo urbano no consolidado) con el régimen jurídico aplicable al "suelo urbanizable sin programa de ejecución aprobado", de acuerdo con la Ley 1/2001, del Suelo y Ordenación del Territorio de Extremadura (LSOTEX). Sin embargo, la AP entiende que no han de confundirse ambas cuestiones y que en virtud del principio de intervención mínima del Derecho Penal, explicando a estos efectos cada una de las clases de suelo recogidas en la normativa regional, llegando a la conclusión de que el CP se refiere a los delitos contra la ordenación del territorio cometidos en suelo no urbanizable, razón por la cual absuelve al propietario del inmueble y autor de las obras. Esta absolución conlleva el que se desestime la demolición de lo construido, petición que se solicitaba únicamente respecto de este acusado y por este delito, no respecto de la acusación contra el alcalde.

En cuanto a la responsabilidad del alcalde, la Audiencia subraya que el art. 320 del CP sanciona una acción que consiste en haber "resuelto o votado a favor de la concesión de licencias contrarias a las normas urbanísticas vigentes, a sabiendas de su injusticia”, entendiendo que contraria a la norma urbanística vigente lo es tanto una licencia que autoriza una obra en suelo no urbanizable como una licencia que autoriza una obra en suelo urbano cuando todavía "no es posible la realización de actos edificatorios o de implantación de usos", concepto que va más allá de la estrecha concepción de la arbitrariedad recogida en el art. 404 del CP puesto que se refiere a las licencias otorgadas en contra de la normativa urbanística vigente. De esta manera, la Audiencia hace suyo el argumento de que no puede discutirse tal vulneración del ordenamiento por mucho que se tratara de una obra de ampliación "respecto de una edificación más que consolidada desde hace años que está en el centro del pueblo, que no tiene ningún elemento constructivo de especial protección, que carece de interés paisajístico, que goza de todas las infraestructuras necesarias, luz, agua, alcantarillado, acerado" como señala la defensa, y a pesar de que "las obras de ampliación se adecuan a la ordenación detallada reflejada en las normas para la clave 1, esto es, por un lado se ajustan a las alineaciones oficiales que separan el suelo que debía tener un destino público de los solares con aprovechamiento lucrativo, por otro al ser una ampliación de uso residencial cumplen con el uso que la norma fija como principal permitido, y cumple además con la altura máxima fija por la norma en 7 metros", tal y como se indica en el informe técnico de la Oficina de Gestión Urbanística de la Mancomunidad, lo cierto es que según ese mismo informe técnico "no podrá concederse licencia de obra sin la aprobación previa del proyecto de compensación", pues, "al tratarse de terrenos incluidos en una unidad de actuación, antes 
de cualquier actuación edificatoria debería haberse procedido al previo desarrollo completo de la misma, esto es, aprobación y adjudicación del programa de ejecución, aprobación definitiva del proyecto de reparcelación y aprobación definitiva del proyecto de urbanización"; y, tal y como establece la LSOTEX, en el "suelo urbano para el que el planeamiento de ordenación territorial y urbanística establezca o prevea, a efectos de su ejecución, la delimitación de unidades de actuación urbanizadora, no es posible, con carácter general, la realización de otros actos edificatorios o de implantación de usos antes de la ultimación de las obras de urbanización que los de carácter provisional previstos en esta Ley y los correspondientes a infraestructuras y dotaciones públicas”.

Estas circunstancias relativas al deber de conocimiento de la normativa aplicable en el municipio las recalca la Audiencia al estimar que "resulta absolutamente impensable que el Alcalde de la localidad desconozca que un vecino promueve ante el unas gestiones encaminadas a modificar el trazado de una Unidad de Ejecución del planeamiento urbanístico del pueblo, o que desconozca que, al ser rechazada su pretensión, el vecino decidió solicitar a su Ayuntamiento una licencia de obras, si bien esta vez como obra menor (la que en su día la que fue rechazada previo informe desfavorable de 5 de febrero de 2.001 fue una solicitud de licencia de obra mayor acompañada de su correspondiente proyecto visado por el Colegio Oficial de Arquitectos de Extremadura), licencia que el alcalde acusado le concedió pese a que constaba en el expediente un informe del secretario en el que se indicaba expresamente que "no procede el otorgamiento de la licencia por carecer de informe técnico de los servicios técnicos municipales". De ahí que condene al alcalde por este tipo de delito, cuya pena reduce por las dilaciones indebidas que se dieron en el presente caso.

En segundo lugar, la SAP de Badajoz, Sección $3^{\mathrm{a}}$, n⿳⺈ 87/2016, de 18 de mayo, trata un supuesto de cebos envenenados destinados a la caza, uno de los casos más graves de la intervención en el medio natural. Los hechos tratan de la colocación del veneno "clorpirifo" en una finca colindante con una reserva de caza, hecho contra el que el condenado por el Juzgado de lo Penal de Mérida esgrimía que cualquiera podía haberlo colocado en su propiedad. Frente a este argumento, la Audiencia valora positivamente las pruebas aportadas por el SEPRONA, le hecho de que se encontrase una factura por la compra de $25 \mathrm{~kg}$. del producto venenoso, que solo se hubiera hallado veneno en su finca y no en el resto de las colindantes con la reserva de caza y el hecho de una condena anterior por envenenamiento y el que pese a la evidencia de que el acusado cuidara 
personalmente de sus viñedos no llegara a haber advertido la presencia de "montoncitos" (sic) de pienso compuesto con el cebo envenenado, quedándole claro a los magistrados que solo pudo él haber colocado el veneno. La ratio decidendi se basa en la suma de estas pruebas indiciarias, de acuerdo con la jurisprudencia constitucional, para enervar el principio de presunción de inocencia, por lo que la Audiencia Provincial desestima el recurso del infractor. 